\title{
Social Interaction and Stock-Market Participation
}

\author{
Harrison Hong \\ Stanford Business School \\ Jeffrey D. Kubik \\ Syracuse Economics Department \\ Jeremy C. Stein \\ Harvard Economics Department
}

First draft: February 2001

This draft: June 2001

\begin{abstract}
We investigate the idea that stock-market participation is influenced by social interaction. We build a simple model in which any given "social" investor finds it more attractive to invest in the market when the participation rate among his peers is higher. The model predicts higher participation rates among social investors than among "nonsocials". It also admits the possibility of multiple social equilibria. We then test the theory using data from the Health and Retirement Study. Social households-defined as those who interact with their neighbors, or who attend church-are indeed substantially more likely to invest in the stock market than non-social households, controlling for other factors like wealth, race, education and risk tolerance. Moreover, consistent with a peereffects story, the impact of sociability is stronger in states where stock-market participation rates are higher.
\end{abstract}

We are grateful to the National Science Foundation for research support, and to Ed Glaeser, Michael Kremer, David Laibson, Michael Morris, Mark Rubinstein, Lara Tiedens, Tuomo Vuolteenaho and Ezra Zuckerman for their comments and suggestions. A special thanks to Jun Liu for some very helpful modeling tips. Thanks also to seminar participants at Berkeley, Chicago, Columbia, Ohio State, Rochester and Stanford. 


\section{Introduction}

In 1998, 48.9\% of American households owned stock, either directly, or through mutual funds or various retirement vehicles such as $401(\mathrm{k})$ plans or IRAs. ${ }^{1}$ While this number may appear low in some absolute sense-particularly in light of the historically high returns to investing in the stock market - it actually represents an all-time peak in the U.S., and a dramatic increase from earlier years. For example, less than a decade earlier, in 1989, the participation rate stood at only $31.6 \%$; even as late as 1995 it was still at just $40.4 \%$.

What are the underlying determinants of the stock-market participation rate? This question is an important one, for a number of reasons. First, as argued by, e.g., Mankiw and Zeldes (1991), Brav, Constantinides and Gezcy (1999), Heaton and Lucas (1999) and Vissing-Jorgensen (1999), the participation rate can have a direct effect on the equity premium; thus an understanding of what drives participation can help shed light on the equity-premium puzzle of Mehra and Prescott (1985).

Second, certain policy debates hinge crucially on one's view of why so many households opt not to participate in the stock market. Consider proposals which would have the government invest some portion of social security tax proceeds in the stock market. On the one hand, if one takes the perspective of a full-information, frictionless model with optimizing households - in which those who sit out do so simply because they find the market's risk-return profile unattractive — standard arguments suggest that there is nothing to be gained by having the government invest in the market on their behalf. On the other hand, if households do not participate because of a lack of

\footnotetext{
${ }^{1}$ The numbers in this paragraph are from the Survey of Consumer Finances, as reported by Bertaud and Starr-McCluer (2000).
} 
information about market opportunities, or because other frictional costs deter them from doing so, the case for these proposals can, at a minimum, begin to make logical sense. ${ }^{2}$

A few basic facts about the determinants of household participation in the stock market are already well-known. ${ }^{3}$ First, participation is strongly increasing in wealth. This can be understood by thinking of participation as involving fixed costs; wealthier households have more to invest, and so the fixed cost is less of a deterrent to them. Vissing-Jorgensen (2000) builds a model in which fixed costs of participation are incurred on a per-period basis, and estimates that such costs have to be on the order of $\$ 200$ per year to explain observed participation rates. Of course, such large numbers beg the questions of what these black-box fixed costs actually represent, and whether one should think of them as being similar across different types of households.

Stock-market participation has also been found to be increasing in household education. One natural interpretation of this fact is that education reduces the fixed costs of participating, by making it easier for would-be investors to understand the market's risk-reward tradeoffs, to deal with the mechanics of setting up an account and executing trades, etc. ${ }^{4}$ Finally, there is also a pronounced link between race and participation, with white, non-Hispanic households having much higher participation rates, controlling for wealth and education.

In this paper, we add to this line of work by considering the possibility that stockmarket participation is influenced by social interaction. A priori, this would seem to be a promising hypothesis, given the growing body of empirical research that speaks to the

\footnotetext{
${ }^{2}$ See Abel (2000) and Campbell et al (1999) for explicit analyses along these lines.

${ }^{3}$ These facts are documented by, e.g., Vissing-Jorgensen (2000) and Bertaud and Starr-McCluer (2000).

${ }^{4}$ Bernheim and Garrett (1996) and Bayer, Bernheim and Scholz (1998) find that financial education in the workplace increases participation in retirement plans.
} 
importance of peer-group effects in a variety of other contexts. ${ }^{5}$ Notably, some of this work finds evidence of peer effects in financial settings that are suggestively close to the one we have in mind-e.g., Duflo and Saez (2000) and Madrian and Shea (2000) demonstrate that an individual's decision of whether or not to participate in particular employer-sponsored retirement plans is influenced by the choices of his co-workers.

In the specific setting of the stock market, there are at least two broad channels through which social interaction might influence participation. The first is word-of-mouth or observational learning (Banerjee (1992), Bikchandani, Hirshleifer and Welch (1992), Ellison and Fudenberg $(1993,1995)) .{ }^{6}$ For example, potential investors may learn from one another either about the high returns that the market has historically offered, or about the details of how to execute trades. Second, in the spirit of Becker (1991), a stockmarket participant may get pleasure from talking about the ups and downs of the market with friends who are also fellow participants, much as he might enjoy similar conversations about restaurants, books, movies or local sports teams in which there is a shared interest.

We build a model which captures these ideas in a simple way. Our model has two types of investors: "non-socials" and "socials". The non-socials are similar to the investors in Vissing-Jorgensen (2000): they each face fixed costs of participation, but these fixed costs are not influenced by the behavior of others. In contrast, any given

\footnotetext{
${ }^{5}$ Examples include Case and Katz (1991), Glaeser, Sacerdote and Scheinkman (1996), and Bertrand, Luttmer and Mullainathan (2000). Glaeser and Scheinkman (2000) provide a survey with more references.

${ }^{6}$ Shiller and Pound (1989) present survey data on the diffusion of information among stock-market investors by word of mouth. Kelly and Grada (2000) find evidence that, during banking panics, bad news about banks spreads via word of mouth in neighborhoods.
} 
social investor finds it more attractive to invest in the market-i.e., his fixed costs are lower — when the participation rate among his peers his higher.

The model's most basic and unambiguous prediction is that there will be higher participation rates among social investors than among non-socials, all else equal. The model also suggests that the participation rate among socials can be more sensitive to changes in other exogenous parameters-i.e., there can be "social multiplier" effects. Consider the consequences of a change in technology (e.g., web-based trading) that makes the direct physical costs of participation lower for all investors. In many cases, this technological change will have a greater impact on the participation of socials than on that of non-socials, because of the positive externalities that socials confer on one another. Indeed, when these positive externalities are strong enough, they can generate multiple equilibria among social investors.

In an effort to test the theory, we draw on data from the Health and Retirement Study (HRS). This survey of roughly 7500 households has a variety of information on wealth, asset holdings, demographics, etc. But most relevant for our purposes, it also asks respondents several questions which allow us to create empirical analogs to our model's notion of "non-social" and "social" households. In particular, the survey asks whether households interact with their neighbors, or attend church.

We find that more social households - defined as those who answer "yes" to these questions - are indeed more likely to invest in the stock market, controlling for other factors like wealth, race and education. The effects of sociability are both strongly statistically significant, as well as economically important. Across the entire sample, households that either know their neighbors or that attend church have a roughly four 
percent higher probability of participating in the stock market, all else equal. Among white, educated households with above-average wealth — those who are typically most likely to be on the cusp of the participation decision — the marginal effect of sociability is substantially stronger, reaching eight percent in some specifications.

While the HRS data allow us to address our theory in a straightforward way, they also suffer from an important drawback. The measures of sociability that we take from the HRS - whether households know their neighbors or attend church-reflect endogenous choices, and hence may capture information not just about the degree of social interaction per se, but also about other personality traits that may be associated with the propensity to invest in the stock market. For example, sociable people may be more bold, and hence less risk-averse when it comes to investing. Or they may be more optimistic, and hence have higher expectations for future stock-market returns.

We attempt to address these possibilities in two distinct ways. First, we are fortunate in that the HRS data allow us to construct proxies for other potentially relevant personality traits such as risk tolerance and optimism. When entered as additional controls in the stock-market participation regressions, these proxies tend to come in significantly, and with the expected signs - suggesting that they are doing a good job of measuring what they are supposed to measure - but they have little effect on our sociability variables.

Second, we take advantage of the fact that our theory has subsidiary implications that the sociability-as-surrogate-for-personality alternative does not necessarily have. In particular, if social households invest more because of their interactions with other investors, then the marginal effect of sociability ought to be more pronounced in areas 
where there is a high density of stock-market participants. ${ }^{7}$ To take an extreme example, if a social household lives in a state where nobody else invests in the stock market (and it doesn't interact with anybody out-of-state) then according to our theory we should not see any effect of sociability on participation for this household. In contrast, if our social variables are simply proxies for, e.g., individual risk tolerance, then one might expect these variables to attract the same positive coefficients in participation regressions regardless of what kind of state the household lives in.

Consistent with our theory, we document that the impact of household sociability is indeed stronger in states where stock-market participation rates are higher. These cross-state differentials are very substantial. In "high-participation" states (those with average participation rates in the top one-third of the sample) sociability generates an increase in the participation rate that averages roughly seven to nine percent across all demographic groups; in "low-participation" states the sociability effect is close to zero. Moreover, this cross-state pattern distinguishes our social variables from our measure of risk-tolerance - the risk-tolerance variable shows no differential effect across states.

These results help to allay concerns that our proxies for sociability are picking up other personal attributes that have nothing to do with social interaction. But there is another, more subtle version of the endogeneity critique that we cannot address, and that must be borne in mind when interpreting our findings. In the context of a word-ofmouth-learning story, it may be that socials have a higher propensity to participate in the market not because they have a greater number of informative interactions with their peers, but rather because they are better listeners and hence learn more from a given level

\footnotetext{
${ }^{7}$ This logic parallels that of Bertrand, Luttmer and Mullainathan (2000), who find that being surrounded by others who speak the same language increases welfare use more for those from high-welfare-using groups.
} 
of interaction. ${ }^{8}$ In other words, because of the endogeneity problem, one would not want to draw the same kind of strong causal conclusions that one might from a randomized experiment (as in Sacerdote (2000)). Specifically, it does not follow from our results that if a non-social household were somehow forced to spend more time with its neighbors it would be more likely to participate in the market. We do not think that this caveat makes our results less interesting from a positive-economics perspective. But it needs to be remembered when thinking about the normative implications of these results.

The remainder of the paper is organized as follows. We begin in Section II by developing a model that illustrates the link between social interaction and stock market participation, and that forms the basis for our subsequent tests. In Section III we describe our data set, and in Section IV we present our empirical results. Section V concludes.

\section{The Model}

We consider a very simple one-period model in which investors can put their money in either a riskless bond or the stock market. For simplicity, the interest rate on the bond is taken to be zero. The net excess return on the market, given by $r$, has a binomial distribution: with probability $\pi, r=r_{d}$, and with probability $(1-\pi), r=r_{u}$. We further assume that $r_{d}<0<r_{u}$ (so that there are no arbitrage opportunities) and also that $\pi r_{d}+(1-\pi) r_{u}>0$ (so that the expected excess return on the market is positive).

Investors have initial wealth of $w$ and constant-relative-risk-aversion (CRRA) preferences over terminal wealth $W$, given by $U(W)=W^{1-\gamma} /(1-\gamma)$, where $\gamma>0$. Assuming for the moment that an investor does in fact participate in the stock market, let

\footnotetext{
${ }^{8}$ Alternatively, socials may derive a greater amount of enjoyment than non-socials from a given amount of talking about the market with their friends.
} 
$h$ denote the fraction of his wealth allocated to the market. Then the objective of the investor is to maximize with respect to $h$ the following:

$$
\left[\pi\left(w\left(1+h r_{d}\right)\right)^{1-\gamma}+(1-\pi)\left(w\left(1+h r_{u}\right)\right)^{1-\gamma}\right] /(1-\gamma) .
$$

The first-order condition for this problem is given by:

$$
\pi\left(w\left(1+h r_{d}\right)\right)^{-\gamma} r_{d}+(1-\pi)\left(w\left(1+h r_{u}\right)\right)^{-\gamma} r_{u}=0 .
$$

Solving for $h$, the optimal fraction of the portfolio allocated to stocks is:

$$
h^{*}=(1-m) /\left(m r_{u}-r_{d}\right),
$$

where $m=\left(-(1-\pi) r_{u} /\left(\pi r_{d}\right)\right)^{-1 / \gamma}$. Note that $m<1$ (because the expected excess return on the market is assumed to be positive) and so $h^{*} \geq 0$.

Plugging $h^{*}$ back into objective function, the value function for an investor who participates in the market, $V_{P}$, is given by:

$$
V_{P}=A w^{1-\gamma /(1-\gamma)}
$$

where $A=\left(\left(r_{u}-r_{d}\right) /\left(m r_{u}-r_{d}\right)\right)^{1-\gamma}\left(\pi m^{1-\gamma}+(1-\pi)\right)$. It then follows that the certaintyequivalent wealth for an investor who participates in the market, $w_{P}$, can be written as: 
where $\alpha=A^{1 /(1-\gamma)}>1$.

Now let us turn to the question of whether a given investor participates in the stock market in the first place. We distinguish between two classes of investors: "nonsocials" and "socials". Each non-social $i$ views stock-market participation as entailing a certain fixed cost of $\theta c_{i}$, which is independent of the behavior of all other investors. So a non-social participates in the market only if the certainty-equivalent gain in wealth associated with doing so exceeds this fixed cost. This requires:

$$
w_{P}-w=(\alpha-1) w>\theta c_{i}
$$

Suppose we observe a cohort of non-socials for which only the idiosyncratic participation-cost parameter $c_{i}$ varies within the cohort. (That is, all non-socials in the cohort have the same initial wealth $w$ and risk aversion $\gamma$, as well as the same common participation-cost parameter $\theta$.) Let $c_{i}$ be distributed according to a cumulative distribution function $G\left(c_{i}\right)$. The fraction of the non-social cohort that participates, denoted $p_{n}$, is then given by:

$$
p_{n}=G((\alpha-1) w / \theta)
$$

Thus the participation rate among a cohort of non-socials is - as would be expected-increasing in the cohort's wealth $w$, and decreasing in the cohort's common 
participation-cost parameter $\theta$. The participation rate also depends on the cohort's riskaversion parameter $\gamma$, since $\alpha$ is a function of $\gamma$, although we have not been able to establish that this last relationship is monotonic.

Socials differ from non-socials in that their net cost of participating in the market is influenced by the participation choices of their peers. Specifically, each social interacts with other socials who have the same values of $w, \gamma$ and $\theta$; as before, only $c_{i}$ varies within a cohort of socials. ${ }^{9}$ Denote by $p_{s}$ the fraction of socials in a cohort who participate in the stock market. We assume that the net cost of participation for each social in the cohort is given by $\theta c_{i}-B\left(p_{s}\right)$, where $B(0)=0$ and $d B / d p_{s}>0$. This captures the idea that the cost to any individual social of participating in the market is reduced when more of his peers participate.

As noted in the Introduction, there are several concrete interpretations that can be attached to this formulation. And depending on the specific story being told, the actual social interaction may take place either before or after the decision to participate in the market is made. For example, in the case of word-of-mouth learning about the market's risk/return characteristics, the interaction takes place before any investment. However, in the case of getting utility from talking with friends about the market, one can imagine that a social would invest based just on the prospect of future interactions.

In either case, a given social participates if:

\footnotetext{
${ }^{9}$ The assumption that only $c_{i}$ varies within a cohort, while $w, \gamma$ and $\theta$ are fixed, is made for simplicity. It is straightforward - albeit messier - to allow these other parameters to vary within a cohort of socials.
} 


$$
(\alpha-1) w+B\left(p_{s}\right)>\theta c_{i}
$$

This implies that, in equilibrium, the participation rate among socials, $p_{s}$, satisfies:

$$
p_{s}=G\left(\left((\alpha-1) w+B\left(p_{s}\right)\right) / \theta\right)
$$

Equation (9) allows us to establish the following result.

Proposition 1: In any interior equilibrium, for given values of $w, \gamma$ and $\theta$, the participation rate among socials is higher than among non-socials, $p_{s}>p_{n}$.

It should also be noted that there can be multiple equilibria in the social case. A sufficient condition to rule them out is that the slope of $G\left(\left((\alpha-1) w+B\left(p_{s}\right)\right) / \theta\right)$ with respect to $p_{s}$ be less than one everywhere, i.e., that $(g / \theta) d B / d p_{s}<1$.

Example 1 (Unique social equilibrium): Assume that $B\left(p_{s}\right)=b p_{s}$, that $c_{i}$ is uniform on $[0,1]$ and that $b<\theta$. Then, assuming an interior solution, the equilibrium condition for $p_{s}$ in equation (9) reduces to: ${ }^{10}$

\footnotetext{
${ }^{10}$ The assumption that $B\left(p_{s}\right)=b p_{s}$ might be motivated as follows. After making his participation decision, each social meets up with exactly one member of his cohort, and derives utility of $b$ if that person is also a stock-market investor, so that they can talk about the market together. Thus $b p_{s}$ represents the expected utility from peer-group interaction at the time the participation decision is made.
} 


$$
p_{s}=\left((\alpha-1) w+b p_{s}\right) / \theta \text {. }
$$

Thus the unique equilibrium participation rate among socials is given by:

$$
p_{s}=\operatorname{Min}[(\alpha-1) w /(\theta-b), 1] \text {. }
$$

In contrast, for non-socials the participation rate is:

$$
p_{n}=\operatorname{Min}[(\alpha-1) w / \theta, 1] \text {. }
$$

This example illustrates in a simple way how social interactions can lead to multiplier effects from changes in wealth, risk aversion or direct participation costs. In particular, it is easy to see that as long as we are in an interior solution, the absolute value of the derivative of $p_{s}$ with respect to either $\alpha, w$, or $\theta$ is always greater than the absolute value of the corresponding derivative of $p_{n}$ with respect to these parameters. ${ }^{11}$ And the larger is the sociability parameter $b$, the greater is the multiplier effect.

Example 2 (Multiple social equilibria): Assume that $B\left(p_{s}\right)=b\left(3 p_{s}{ }^{2}-2 p_{s}{ }^{3}\right)$ and that $c_{i}$ is uniform on $[0,1]$. Then, assuming an interior solution, the equilibrium condition for $p_{s}$ in equation (9) reduces to: ${ }^{12}$

\footnotetext{
${ }^{11}$ This statement about multipliers generalizes to any arbitrary $B\left(p_{s}\right)$ function, so long as $c_{i}$ continues to be uniformly distributed. It need not hold, however, for alternative distributions of $c_{i}$.

${ }^{12}$ In keeping with the previous example, the assumption that $B\left(p_{s}\right)=b\left(3 p_{s}{ }^{2}-2 p_{s}{ }^{3}\right)$ can be motivated by imagining that after making his participation decision, each social meets up with three members of his cohort, and derives utility of $b$ only if at least two of the others are also stock-market investors. (In which case there is enough interest among members of the group for them to talk about the market together.)
} 


$$
p_{s}=\left((\alpha-1) w+b\left(3 p_{s}^{2}-2 p_{s}^{3}\right)\right) / \theta \text {. }
$$

For the sake of a specific numerical example, suppose that we have $(\alpha-1) w=0.02$; $b=0.9$; and $\theta=1$. In this case, the three roots of the cubic equation in (13) are given by $p_{s}=0.0212 ; p_{s}=0.5894 ;$ and $p_{s}=0.8894$. Of these three roots, the lowest and highest represent locally stable equilibria. Thus we conclude that for socials, there are two potential equilibria, involving participation rates of $p_{s}=0.0212$ and $p_{s}=0.8894$. In contrast, for non-socials, the unique equilibrium participation rate is $p_{n}=0.02$.

When we turn to the empirical work below, our main focus will be on testing Proposition 1, and on ensuring that the results of these tests are not contaminated by endogeneity biases. Nevertheless, it is worth briefly highlighting some of the model's other significant empirical implications.

First, the kinds of social multipliers that are evident in Example 1 may be helpful in thinking about changes in aggregate stock-market participation over time. As noted above, the participation rate has increased dramatically over the last decade or so. One candidate explanation for this phenomenon is that the growing prominence of mutual funds, along with the introduction of web-based trading, have together led to a systematic decline in average costs of participation, which corresponds to a reduction in the parameter $\theta$ in our model. ${ }^{13}$ If so, social-interaction effects may have helped to give this $\theta$-shock much more kick than it otherwise would have had. This hypothesis can in

\footnotetext{
${ }^{13}$ Choi, Laibson and Metrick (2000) present direct evidence on the consequences of web-based trading.
} 
principle be tested by looking to see if the participation rate of socials has increased more rapidly in recent years than has the participation rate of non-socials. As discussed below, we make an effort in this direction, though data limitations prevent us from going as far as we would like.

Second, to the extent that people tend to interact disproportionately with members of their own racial/ethnic groups, the multiple equilibria seen in Example 2 could potentially shed some light on the puzzle of why black and Hispanic households tend to be stuck at much lower participation rates, even when they are wealthy and highly educated. Loosely speaking, the multiple equilibria suggest that an ethnic group's past history with respect to participation may — by affecting which equilibrium is chosenexert an important influence on current outcomes, above and beyond the effects of any current conditions such as wealth and education. ${ }^{14}$

\section{Data}

Our data come from Health and Retirement Study (HRS) administered by the Institute for Social Research at the University of Michigan. ${ }^{15}$ This survey was first conducted in 1992 (this is referred to as Wave 1 of the survey), and covers approximately 7,500 households who have a member born during the period 1931-41. ${ }^{16}$ Thus the average age of target respondents at the time of Wave 1 is roughly 56 years. Follow-up Waves 2, 3, and 4, covering the same households, were conducted in 1994, 1996 and

\footnotetext{
${ }^{14}$ With regard to the role of history, Chiteji and Stafford (1999) document that young adults are much more likely to participate in the stock market if their parents did.

15 The dataset, along with all the survey questions and supporting documentation, is available at: www.umich.edu/ hrswww/

${ }^{16}$ The HRS is a representative sample within this age group, except that blacks, Hispanics and Florida residents are $100 \%$ oversampled.
} 
1998 respectively. Our analysis focuses primarily on the data from Wave 1 of the HRS. We have re-run all our tests using the data from the later waves; as might be expected, given that these later waves cover the same households, they contain very little independent information, and lead to virtually identical results. ${ }^{17}$

Beginning in 1998, the HRS also added a new cohort to the survey, composed of households with a member born during the period 1942-47, and dubbed the "war baby" cohort. The average age of the war babies in 1998 is approximately 54 years, very similar to that of the original HRS sample in 1992. This 1998 war-baby sample is of obvious interest, for two reasons. First, we would like some out-of-sample verification of our results from the 1992 survey. And second, it would be interesting to test the model's intertemporal social-multiplier prediction - to see if, as the overall participation rate has increased over the 1990's, the differential between socials and non-socials has widened.

Unfortunately, the war-baby sample is much smaller, covering only around 1400 households, which seriously limits our statistical power. Even more problematic, this version of the survey omits several of the questions that are most crucial for us, leaving us able to create only one of the three measures of social interaction that we use in the original 1992 HRS sample, and forcing us to drop other controls. Thus our analysis of the war-baby sample is restricted to just a couple of very basic regressions (see Table 7 below); unless explicitly noted otherwise, everything else we discuss from now on refers to the 1992 wave of the original HRS sample.

\footnotetext{
${ }^{17}$ One reason to focus on the first (1992) wave is that there is some attrition among respondents in the later follow-up surveys. (The first-wave interviews are done in person, the others by phone.) Moreover, the rate of attrition is correlated with our key variables - there is more attrition among non-social households.
} 
The HRS includes information on place of residence (by state, along with an urban/rural indicator), age, years of education, race, wealth, income, and marital status. For age, years of education and race, we may have two responses per household —one for the man and one for the woman of the house. We take the "age" and "education" of a household to be the higher of the two reported values. For race, we classify a household as non-white if either member is. ${ }^{18}$ With respect to stock-market participation, the survey asks whether households own stocks, either directly or through mutual funds. However it should be noted that this question only pertains to non-retirement-account assets. The dataset has very little information on assets held in retirement accounts, and so these are omitted in our measure of participation. While there is no reason to expect that this should bias our inferences about the role of social interactions, it does mean that the average participation rates that we report are significantly lower than those obtained from other datasets (e.g., the Survey of Consumer Finances) that include retirement assets in the measure of participation.

To create our measures of social interaction, we focus on three specific questions in the survey. Each of the social questions is answered by only a single member of the household, typically the woman. ${ }^{19}$ The first is: "Of your closest neighbors, how many do you know?" 92.9\% of respondents answer either "all", "most" or "some"; our KnowNeighbors dummy variable takes on the value one for these households, and zero for the remainder who answer "none". The second question is: "How often do you visit with your neighbors?" 63.9\% answer either "daily", "several times a week", "several times a

\footnotetext{
${ }^{18}$ None of our results is sensitive to how we choose to handle these details.

${ }^{19}$ In our regressions, we include a dummy for the sex of the respondent to the social questions.
} 
month", or "several times a year"; our Visit-Neighbors dummy is set to one for these households, and to zero for the remainder who answer "hardly ever". ${ }^{20}$ Finally, the third question is: "How often do you attend religious services?" $76.0 \%$ answer either "more than once a week", "once a week", "two or three times a month", or "one or more times a year"; our Attend-Church dummy is one for these households and zero for the remainder who answer "never".

A large body of work in sociology supports the premise of using these sorts of variables as measures of the extent to which households have informative interactions with one another. Granovetter (1983) surveys much of this work, emphasizing "the strength of weak ties"-i.e., the substantial amount of information that people obtain through interactions with neighbors and casual acquaintances. For example, there is a lot of evidence to the effect that people learn about new jobs through such informal connections, rather than through more formal channels.

As mentioned in the Introduction, we also try to use the survey questions to create proxies for other personality traits. Risk aversion is the most straightforward, since there is a question designed by economists (Barsky et al (1997)) specifically to measure this attribute: “...you are given the opportunity to take a new and equally good job, with a 5050 chance it will double your income and a 50-50 chance it will cut your income by a third. Would you take that new job?" In contrast to the sociability questions, this-like the other "personality-related" questions - is asked separately of each member of a household. Our Risk-Tolerant dummy is one for the $32.5 \%$ of households with at least

\footnotetext{
${ }^{20}$ We are bypassing another similar question, "Do you have good friends in your neighborhood?", because it seems more ambiguous as a measure of social interaction. In particular, we worry that a respondent who interacts regularly with his or her neighbors, but whose best friends live elsewhere, might be inclined to say "no" to this question.
} 
one member who responds "yes", and zero for the remainder where both members answer "no". ${ }^{21}$

Sociability might also be related to optimism, which could in turn influence stockmarket participation. The best we can do on this score is to use the following question: "During the past week, I felt depressed. (All or almost all of the time, most of the time, some of the time, or none or almost none of the time?)" Our premise here is that there is likely to be a link between depression and pessimism. In any case, our Depressed dummy takes on the value one in the $8.3 \%$ of cases where at least one member of the household responds "all or almost all of the time"; in the remaining cases the dummy is set to zero.

It is important to stress however, that while we are using this variable in the hopes that it will control for a purely individual characteristic — namely pessimism — that might be related to participation, it is also plausible that it contains further independent information about the extent of social interaction, since depressed people may well spend less time interacting with others. In this sense, the Depressed dummy differs from the Risk-Tolerant dummy, which seems to be more cleanly interpretable as being strictly about an individual trait, and not about anything having to do with social interaction.

Finally, one might speculate that sociable people are simply more open-minded, and more willing to try new things. The only question that comes close to allowing us to address this idea is: "How difficult is it for you to use a computer or wordprocessor?" Our Low-Tech dummy is one for the $30.9 \%$ of households in which both members answer "don't do", and zero for the remainder of households. An obvious problem in

\footnotetext{
${ }^{21}$ Our results are essentially unchanged if we require both members to respond "yes" in order to classify a household as risk-tolerant. A similar comment applies to our other personality-trait proxies.
} 
interpreting any coefficient on this Low-Tech variable is that unlike risk tolerance or depression, computer use represents an outcome, not a personality trait. And as with the Depressed dummy, there is also the further qualification that even if it contains some information about the personality trait of open-mindedness, it may also capture information about social interaction, to the extent that there are peer effects in the adoption of computers.

Tables 1 and 2 provide an overview of some basic facts about the data. Panel A of Table 1 breaks down participation rates across different demographic groups. Overall, in the whole HRS sample, $26.7 \%$ of households participate in the stock market. (Recall that this is 1992, and that our measure of participation does not include assets held in retirement accounts.) Participation increases sharply with wealth, going from 3.4\% in the lowest quintile of the wealth distribution to $55.0 \%$ in the highest wealth quintile. ${ }^{22}$ There are also strong differences between white/non-Hispanic households and other racial groups, as well as between college-educated and non-college-educated respondents. These differences remain stark even controlling for wealth. For example, in the fourth quintile of the wealth distribution, the participation rate is $43.7 \%$ for white/nonHispanics, and only $21.3 \%$ for other races. Similarly, in the same wealth quintile, the participation rate is $50.1 \%$ for college graduates, and only $35.4 \%$ for non-graduates.

In Panel B of Table 1, we take a crude first look at the effect of social interaction on participation, with a two-way sort based on wealth and each of our three measures of sociability. Although this approach is obviously not a substitute for the more carefully

\footnotetext{
${ }^{22}$ We measure wealth as the value of all assets excluding non-retirement stockholdings. With this measure, the inter-quintile cutoff values are: $\$ 11,000 ; \$ 55,000 ; \$ 116,000$; and $\$ 240,000$. Our principal results are unchanged if we include stockholdings in our wealth measure, and they are also not sensitive to whether or not we include retirement wealth.
} 
controlled regressions that follow, it makes it clear that the basic patterns emerge in even the most simple tabulations of the data. Using the Know-Neighbors measure of interaction, $12.3 \%$ of non-social households participate in the market, while $27.8 \%$ of social households do. With Visit Neighbors, the corresponding figures are $22.8 \%$ and 28.9\%, while with Attend Church they are $23.5 \%$ and $27.7 \%$. In addition, when the sample is stratified based on wealth, it appears that the differences between social and non-social households become more pronounced as wealth increases-indeed, virtually all of the action in this respect comes from the top three wealth quintiles.

In Table 2, we look at the correlations between our three measures of sociability, as well as between these measures and the other independent variables that will enter our specifications. Not surprisingly, Know Neighbors and Visit Neighbors are highly correlated, with a correlation coefficient of 0.37 . On the other hand, both of these measures are more weakly correlated with Attend Church, with coefficients of only 0.08 and 0.09 respectively. Thus it seems fair to say that the Attend Church variable offers relatively independent information on sociability above and beyond that contained in the first two variables.

None of the sociability measures is all that highly correlated with the other personality proxies, though there are some noteworthy differences. On the one hand, Risk Tolerant is essentially uncorrelated with all the social variables. In contrast, both Depressed and Low-Tech have statistically significant correlations of -0.07 and -0.06 respectively with Know Neighbors. This suggests that social people may indeed be happier (and perhaps more optimistic) as well as more open to new experiences. It also reinforces the point made above, namely that unlike the Risk Tolerant variable, 
Depressed and Low-Tech may themselves be indirect proxies for the degree of social interaction.

Finally, there are some modest correlations between our sociability measures and the demographic variables. White, educated and wealthy households are all somewhat more likely to both know their neighbors and visit them, with pairwise correlation coefficients in the range of 0.04 to 0.09 . On the other hand, non-white households are markedly more churchgoing - the correlation between the White/Non-Hispanic dummy and the Attend-Church dummy is -0.15 .

\section{Empirical Results}

\section{A. Baseline effect of social interaction on stock-market participation}

Table 3 presents our baseline results. All regressions are run by OLS, with the dependent variable an indicator that takes on the value one when a household owns stock, and zero otherwise. ${ }^{23}$ There are nine columns, corresponding to three different specifications with each of our three sociability measures-Know Neighbors, Visit Neighbors and Attend Church. In columns (1), (4) and (7), the social variable enters along with the Risk Tolerant dummy, years of education, age, a white/non-Hispanic dummy, an urban dummy, a marital-status dummy, a sex-of respondent dummy, and four dummies corresponding to the second, third, fourth and fifth quintiles of the wealth distribution.

In columns (2), (5) and (8), the only modification is that we use 19, rather than four wealth dummies, which means that we have now chopped up the wealth distribution

\footnotetext{
${ }^{23}$ Given the dichotomous nature of our left-hand-side variable, we have redone all our tests using probit and logit specifications, with very similar results.
} 
into five-percent increments. This allows us to get a tighter wealth control, but makes it impractical to display the individual coefficients on all these dummies. Finally, in columns (3), (6) and (9), we add several further controls: 19 income dummies; dummies for each year of age and education (which go in place of the linear age and education terms and represent a more conservative approach to controlling for these factors); state dummies; and the Depressed and Low-Tech variables.

As can be seen, the results paint a consistent picture. Consider first the Know Neighbors measure of social interaction. The coefficients on this variable are very close to 0.040 in all three regressions, implying that social households have a four percent higher probability of participating in the stock market, all else equal. Moreover, in each case the coefficients are statistically significant at the one percent level. The Visit Neighbors variable looks to be a weaker version of Know Neighbors, with coefficients that range between 0.022 and 0.025 , but that are still statistically significant. Finally, the Attend Church variable delivers coefficients that are comparable to those on Know Neighbors in the first two regressions - on the order of 0.036 - but that tail off a bit, to a value of 0.027 , when the full set of controls is added.

The coefficients on some of the other controls are worth a brief mention. To begin with, we confirm earlier work by finding very powerful effects of education, race and wealth on stock-market participation. For example, our estimates suggest that white/non-Hispanics have about a ten percent greater participation rate than other groups, all else equal. The Risk Tolerant dummy has the expected positive sign, and with a value of around 0.037 across most of the specifications, it appears to be economically as well as 
strongly statistically significant. The Depressed and Low-Tech indicators are both negative, as anticipated, and significantly so.

However, we caution against attaching the same kind of causal interpretation to the Low-Tech proxy that one might naturally lend to, e.g., the Risk Tolerant variable. As discussed above, with Low-Tech, we are in effect running one type of endogenous outcome (stock-market participation) on another (computer use). The goal in this case is not to make a structural inference, but rather to illustrate that, to the best of our ability to control for a personality trait like open-mindedness, this control does not seem to affect the coefficients on our key sociability indicators.

The results in Table 3 speak to the average effects of sociability across all demographic groups. In Table 4, we investigate how the marginal effect of social interaction varies with race, education and wealth. Based on our model, there are two distinct reasons to expect that the coefficients on the social variables would be higher among white, educated and wealthy households. ${ }^{24}$ First, to the extent that households interact with others having similar demographic characteristics, peer effects should be stronger among those groups with high participation rates. To take an extreme example, no amount of interaction is likely to foster much information-sharing about the stock market if it takes place among non-white/Hispanic households in the first quintile of the wealth distribution, where the overall participation rate is only $1.17 \%$ (see Table 1 ).

Second, even if social interaction did somehow lead to the same informational (or other) benefit across all demographic groups, this benefit would be less likely to cause a shift from non-participation to participation among those groups for whom the gains from

\footnotetext{
${ }^{24}$ Moreover, the simple two-way sorts in Panel B of Table 1 suggest that the effect of sociability is much stronger among wealthier households.
} 
participation are so small relative to the non-social-related component of fixed cost that they tend to be well below the participation threshold. In other words, if we look at groups for which $(\alpha-1) w$ is typically much less than $\theta c_{i}$, we are on average so far from the participation/non-participation cusp that any benefits from social interaction do not have much impact on observed behavior. Note that in this case, an exactly identical argument applies to other participation-enhancing variables, such as risk tolerance: it is unlikely that increases in risk tolerance will have nearly as much effect on stock-market participation among groups for which $(\alpha-1) w$ is typically much less than $\theta c_{i}$.

Table 4 confirms these predictions. In this table, everything is a variation on the specifications in columns (2), (5) and (8) of Table 3. That is, the regressions include-in addition to the displayed terms involving the social variables - the Risk Tolerant dummy, years of education, age, a white/non-Hispanic dummy, an urban dummy, a marital-status dummy, a sex-of respondent dummy, and 19 wealth dummies, all of which are suppressed for compactness. Each social variable now enters not only alone, but also interacted with the White, Educated and Wealthy indicator, which takes on the value one for those households who are white/non-Hispanic, who are at least high-school graduates and who have wealth above the sample median. These households represent $39.1 \%$ of the total sample, and have an average participation rate of $49.1 \%$, as compared to the remaining households, who have an average participation rate of only $12.3 \%$.

The interaction terms are large in magnitude, and statistically significant in two out of three cases. By summing the raw social coefficient with the interaction coefficient, one obtains an estimate of the size of the social effect among white, educated, wealthy households. For the Know Neighbors variable, this number is 0.080 , implying that social 
households in this demographic group have an $8.0 \%$ greater participation rate than nonsocial households. For the Visit Neighbors and Attend Church variables, the corresponding numbers are 0.059 and 0.071 respectively. In each case, the effect of the social variable among white, educated, wealthy households appears to be roughly double the size of the unconditional effect across all demographic groups reported in Table 3.

Beyond what is displayed in Tables 3 and 4, we have also experimented with a number of variations on our baseline specifications, in order to further check the robustness of our results. First, we have redone everything with alternative definitions of stock-market participation that require a household to have some minimal level invested in the market (we have tried thresholds of $\$ 2,500, \$ 5,000, \$ 10,000$ and $\$ 25,000$ ) as opposed to just anything over zero, in order to be counted as a participant. ${ }^{25}$ This is an effort to address the possibility that small stakes in the market may reflect activities like investment clubs, which could be correlated with social interaction in a relatively mechanical and uninteresting way. As it turns out, these alternative definitions of participation lead to results that are very similar to those reported in Tables 3 and 4 . Thus these results do not appear to be driven by investors with only trivial stakes in the market.

Second, we have also tried adding several further controls (beyond those shown in columns (3), (6) and (9) of Table 3) to our specifications. These controls include: whether or not the household owns its home; whether the household takes regular vacations; employment status; number of people in the household (i.e., how many children there are at home); and various measures of health. Several of these controls can be motivated as attempts to capture how busy a household is dealing with other things,

\footnotetext{
${ }^{25}$ Among those households who participate in the market, the median amount invested is $\$ 20,000$. The $25^{\text {th }}$ percentile of the distribution is $\$ 5,000$, and the $75^{\text {th }}$ percentile is $\$ 65,000$.
} 
and hence how little free time it has to devote to stock-market investing. For example, a household that has five children, two parents with full-time jobs, and that never takes vacations may simply be too overwhelmed either to interact with its neighbors, or to invest in stocks. And we want to be sure that such a lack-of-free-time effect is not inducing a spurious correlation between our sociability measures and stock-market participation. However, we find that none of the additional controls has any noticeable impact on the coefficients associated with the sociability measures.

\section{B. Effect of social interaction in high-participation and low-participation states}

While the results thus far are consistent with our theory, the worry remains that our social variables are not picking up the effect of social interaction per se, but rather an individual personality trait that is correlated with stock-market participation and that is somehow not adequately captured by either our Risk Tolerant, Depressed or Low-Tech proxies, or by any of the other controls we have tried. In an effort to address this concern, we exploit the fact that our theory has subsidiary implications that the sociability-as-surrogate-for-personality alternative does not. In particular, if social households invest more because of their interactions with other investors, then the marginal effect of sociability ought to be more pronounced in areas where there is a high density of stock-market participants.

The best we can do to operationalize this idea is to look at the states in which households live, since the HRS does not provide more detailed address data. Table 5 presents some information on stock-market participation at the state level. We group states into low, medium and high-participation categories, where a state's participation 
level is measured in one of two ways. In Panel A, we look at the raw participation rate, which for any state is simply the fraction of resident households that own stock. In Panel $\mathrm{B}$, we look at the abnormal participation rate, which for any state corresponds to the state-average-value of the residual in a regression of household participation against: a risk tolerance dummy, years of education, age, a white/non-Hispanic dummy, an urban dummy, a marital status dummy, a sex-of-respondent dummy and four wealth dummies.

As can be seen in Table 5, many of the same states show up as outliers according to either the raw or abnormal measure. Perhaps most strikingly, several largely rural southern states-Alabama, Louisiana, Arkansas, Tennessee, Mississippi and West Virginia — are classified as having low participation rates on either score.

In the context of our model, a state's abnormal participation rate-given that we have taken out the effects of factors like wealth, risk tolerance, education, and race-is most naturally thought of as a measure of the average value of the cost parameter $\theta$ for its residents. For example, a state with a low abnormal participation rate may be one in which there are relatively few stockbrokers per capita, so that residents have less help getting started in the stock market.

This observation suggests another way to think of our empirical strategy, particularly insofar as we rely on abnormal, rather than raw participation rates. When we look to see if the impact of social interaction is more pronounced in a low- $\theta$ (i.e., highabnormal-participation) state, this is effectively a cross-state test of the social multiplier hypothesis. As illustrated in Example 1 above, the model suggests that as we move from a high- $\theta$ environment (Alabama) to a low- $\theta$ environment (Connecticut), participation among socials should increase by more than participation among non-socials. 
Table 6 presents the tests of this hypothesis. The structure is very similar to that of Table 4, with all the same suppressed controls. Now in addition to having our social variables enter by themselves, we also interact them with an indicator variable that takes on the values $\{-1,0,1\}$ depending on whether a state is classified as low, medium or high-participation. ${ }^{26}$ We try basing this indicator both on the raw participation measure, as well as on our preferred abnormal participation measure.

The results are generally encouraging. When we use the abnormal participation measure, the coefficient on the interaction of sociability and state-level participation is positive in all three cases, and strongly statistically significant in both the Know Neighbors and Attend Church regressions. In terms of economic magnitudes, the Know Neighbors regression suggests that differential between social and non-social households is actually a tiny bit negative, at $-0.5 \%$, in a low-abnormal-participation state, but rises to $9.0 \%$ in a high-participation state. With Attend Church, the corresponding numbers are $0.3 \%$ and $6.5 \%$. Clearly, these are economically significant differences.

When we use the raw participation measure, the interaction coefficient in the Know Neighbors regression is unchanged, but that for Attend Church drops off substantially, and is no longer significant. The regressions with our weakest social variable, Visit Neighbors, do not show a statistically significant interaction coefficient in either the raw or abnormal-participation specification, though in both cases these coefficients have the predicted positive sign.

\footnotetext{
${ }^{26}$ Given that our ability to estimate any state's true $\theta$ is imperfect, we do this grouping-rather than simply having each state's own participation rate enter directly in the regression-in an effort to combat measurement error and to improve the precision of our estimates.
} 
To further bolster the case that these results are really telling us something about social effects, in all the regressions in Table 6 we also interact our Risk Tolerant variable with the same state-level participation indicators-i.e., we treat Risk Tolerant in a way that is symmetric to our social measures. The premise here is as follows. We are reasonably confident that the Risk Tolerant variable is capturing information about a personality trait that is relevant for participation but that has nothing to do with social effects. Thus Risk Tolerant should have the same coefficient regardless of what state a household lives in. In other words, Risk Tolerant should not show the same interaction with the state-level participation indicators that our social measures do.

And indeed, Table 6 confirms this hypothesis. While the Risk Tolerant variable continues to attract a highly significant positive coefficient when standing alone, the interaction terms involving Risk Tolerant are small and completely insignificant in all six specifications. Thus Risk Tolerant behaves in a fundamentally different way across states than do our social variables. Again, this lends further weight to the notion that these social variables are not just another personality trait in disguise.

It is worth contrasting our approach to using cross-state variation in Table 6 to other approaches that are common in the peer-effects literature (see, e.g., Glaeser and Scheinkman (2000) for a discussion). In particular, by analogy to some of this other work, we can use our data to demonstrate the following. First, if one adds the mean participation rate in a household's home state to the baseline regression in column (1) of Table 3, it comes in strongly significant, with a coefficient of 0.240 and a t-stat of 3.48. Thus controlling for its own characteristics, a household is substantially more likely to participate in the market if it lives in a high-participation state. Alternatively, one can 
instead add the mean education and wealth levels in a state to the same baseline regression, with the same qualitative result-a household is significantly more likely to participate in the market if it lives in a state with a wealthier and more educated population.

These sorts of results are certainly consistent with the existence of social effects, and are probably the best that one could do without access to the direct measures of sociability that the HRS affords us. But since they do not exploit the interaction of sociability and cross-state variation in participation, they are more subject to alternative interpretations. For example, suppose that brokerage firms endogenously choose to have more branch offices in wealthy states, and that such branch offices facilitate participation. If so, this could explain why either a state's wealth, or its mean participation rate, matters for individual-household participation, even absent any social effects. By contrast, our Table-6 results cannot be explained away in this fashion, so long as one is willing to adopt the identifying assumption that the effect of branch offices on participation is the same for social and non-social households.

\section{A look at the 1998 war-baby survey}

As noted above, in addition to the original 1992 HRS survey, we have a second independent sample of households - those in the war-baby cohort that were surveyed in 1998. Unfortunately, this sample is much smaller-roughly 1400 as opposed to 7500 observations - and it does not include the survey questions that allow us to construct either the Know Neighbors or Attend Church variables. The only social variable that remains is the Visit Neighbors variable, which we have found thus far to yield the 
weakest results of the three. ${ }^{27}$ Also, this version of the survey does not enable us to construct the Risk Tolerant control.

Nevertheless, working with the limited data we do have, we undertake in Table 7 a comparison of the two different samples. We run the exact same regression for each, the specification being the same as that in column (4) of Table 3, except with the Risk Tolerant control dropped. In principle, there are two things that could potentially be accomplished with such a comparison. First, the 1998 data enable us to perform an obvious out-of-sample robustness check on the results from the 1992 survey.

Second, and more ambitiously, one might hope to test the intertemporal socialmultiplier aspect of our theory. Mirroring the overall rise in stock-market participation over the 1990's, the average participation rate among the war babies in 1998 is $32.3 \%$; this represents a $21 \%$ increase from the $26.7 \%$ participation rate among the original 1992 HRS cohort. ${ }^{28}$ If one thinks of this time trend in participation as reflecting an economywide decrease in costs of participation (i.e., a systematic decrease in the parameter $\theta$ ), then our model suggests that participation should have increased more among socials than among non-socials. Or said differently, the existence of a social multiplier implies that the 1998 sample should yield a larger coefficient on the social variable than the 1992 sample. Note that this is essentially just an intertemporal version of the cross-state comparison made in Table 6: in either case the prediction is that there is a smaller coefficient on the social variable in a high- $\theta$ regime (Alabama, or the early 1990's) than in a low- $\theta$ regime (Connecticut, or the late 1990's).

\footnotetext{
${ }^{27} 67.8 \%$ of households visit their neighbors in the 1998 sample, very close to the 1992 -sample value of $63.9 \%$, suggesting that this variable is picking up similar information in both surveys.

${ }^{28}$ Moreover, as pointed out above, the war babies are almost exactly the same age in 1998 as the original HRS respondents were in 1992, so this seems to be a clean comparison.
} 
The point estimates in Table 7 suggest that our intertemporal social-multiplier hypothesis is on target, but there is simply not enough power to state this conclusion with any degree of statistical confidence. In particular, the coefficient on Visit Neighbors goes from a value of 0.20 in the 1992 sample to a value of 0.35 in the 1998 sample, a striking increase of $75 \%$. Unfortunately, with the much smaller sample, the 1998 coefficient is too imprecisely estimated to allow us to reject equality with the 1992 coefficient at conventional levels of statistical significance.

\section{Social interaction and checking-account use}

An interesting recent paper by Guiso, Sapienza and Zingales (2000) finds that in those regions of Italy where "social capital" is high, people make more use of a variety of financial products, including stock-market investments and checking accounts. Following the work of Putnam (1993), Guiso, Sapienza and Zingales argue that social capital — which they measure at the regional level using electoral participation and percapita blood donations-helps to increase the trust that people have in a variety of institutions, including financial institutions.

While the social-capital variables used by Guiso, Sapienza and Zingales are obviously quite different than our social-interaction proxies, one might stretch and argue that our results reflect a similar kind of social-capital mechanism. Perhaps those households that interact with their neighbors or that attend church have more trust in financial institutions generally, and hence are less fearful that they will be ripped off when they put their money somewhere other than under their mattress. 
Although it is hard for us to address this hypothesis fully with our data, we can take a small step by looking at the effect of our social-interaction variables on checkingaccount use. If our variables really are a proxy for a generalized trust in financial institutions, then one might expect them to explain checking-account use as well as stockmarket participation, much as the social-capital variables of Guiso, Sapienza and Zingales do in the Italian data.

In Table 8, we run exactly the same specifications as in columns (2), (5) and (8) of Table 3, except that we replace the stock-market participation indicator on the lefthand-side of the regression with a checking-account-use indicator. (Overall, 78.2\% of the households in our sample have checking accounts.) As can be seen, our social variables do essentially nothing to explain checking-account use. The estimated coefficients are all very small—actually negative in two out of three cases—and never close to statistically significant. Although this is admittedly just a small bit of evidence, it would seem to cut against the hypothesis that these social variables are indicative of a general trust in financial institutions.

A couple of other interesting results appear in Table 8. First of all, the Risk Tolerant dummy attracts a strongly negative and significant coefficient, suggesting that risk-averse households are, not implausibly, more likely to have checking accounts. And the coefficient on the race indicator implies that non-white/Hispanic households are almost $14 \%$ less likely to have checking accounts, all else equal. This is an enormous effect, and it suggests that even though our social variables may not capture trust, there may be substantially less trust of financial institutions among members of some minority groups. 


\section{V. $\underline{\text { Conclusions }}$}

Three significant findings emerge from our analysis of the HRS data. First, social households - those who interact with their neighbors, or who attend church-are more likely to invest in the stock market than non-social households, all else equal. Second, the impact of sociability is much stronger in those states where stock-market participation rates are higher. Third, and by far most tentatively, the differential between social and non-social households appears to have widened over the course of the 1990's, as overall participation rates have climbed sharply.

This evidence is broadly consistent with the hypothesis that social interaction helps to increase stock-market participation. At the same time, we have been somewhat vague as to the exact mechanism by which social interaction promotes participation. We have discussed two possible stories - one having to do with word-of-mouth informationsharing, the other with the enjoyment that people get from talking about the market together - but have made no effort to discriminate between them. And it should be noted that this distinction may be a significant one, particularly with regard to the more dynamic aspects of the theory.

To see why, suppose that the stock market performs poorly over the next several years, leading some investors to get discouraged and withdraw. To what extent do these departing investors create an externality that affects their peers who are already in the market $^{29}$ Under at least some versions of the word-of-mouth information-sharing story, the externality might be expected to be unimportant, since the presumption is that those

\footnotetext{
${ }^{29}$ In any version of our model, there is a clear prediction that departing investors exert a negative influence on the participation decisions of those who have not yet begun to invest in the market.
} 
who are already in the market know whatever it is they need to know about how to invest. However, under the enjoyment-from-talking-about-the-market story, there is an obvious externality, with any individual's decision to leave the market making it more likely that others in his peer group will leave too. One objective for future work might be to try to distinguish between these two possibilities.

In closing, a final point to highlight is the potentially close connection between the ideas presented here and the growing empirical literature on "local preference" in the stock market. A series of papers has demonstrated that investors strongly tilt their portfolios not only towards home-country stocks (French and Poterba (1991), Cooper and Kaplanis (1994), Tesar and Werner (1995), Kang and Stulz (1997)), but also towards the stocks of firms that are headquartered nearby, or that are otherwise more familiar (Huberman (1998), Coval and Moskowitz (1999), Grinblatt and Keloharju (2000)). In many of these papers, the explicit or implicit story being told is that it is easier for investors to learn about nearby stocks. In other words, in the language of our model, $\theta$ is lower for nearby stocks.

If one accepts this interpretation, then our model suggests that social-interaction effects may be helping to amplify whatever aggregate local preference is induced by exogenous cross-stock differences in $\theta$. Thus even if the direct, observable costs to a U.S. investor of buying, say, Japanese stocks are only modestly greater than the costs incurred with U.S. stocks, the social equilibrium may involve a very pronounced homecountry bias. In such an equilibrium, many U.S. investors may be deterred from investing in Japan largely because they do not know anybody else who does. This hypothesis would seem to provide another natural direction for future research. 


\section{References}

Abel, A., 2000, "The effects of investing Social Security funds in the stock market when fixed costs prevent some households from holding stocks," Wharton working paper, forthcoming in American Economic Review.

Banerjee, A., 1992, “A simple model of herd behavior," Quarterly Journal of Economics 107, 797-817.

Barsky, R., Kimball, M., Juster, F.T., and Shapiro, M., 1997, "Preference parameters and behavioral heterogeneity: An experimental approach in the Health and Retirement Study," Quarterly Journal of Economics 112, 537-579.

Bayer, P., Bernheim, B.D., and Scholz, K., 1998, "The effects of financial education in the workplace: Evidence from a survey of employers," NBER working paper.

Becker, G.S., 1991, “A note on restaurant pricing and other examples of social influences on price," Journal of Political Economy 99, 1109-1116.

Bernheim, B.D., and Garrett, D.M., 1996, "The determinants and consequences of financial education in the workplace: Evidence from a survey of households," NBER working paper.

Bertaut, C. and Starr-McCluer, M., 2000, "Household portfolios in the U.S.," Board of Governors of the Federal Reserve working paper.

Bertrand, M., Luttmer, E. and Mullainathan, S., 2000, "Network effects and welfare cultures," Quarterly Journal of Economics 115, 1019-1055.

Bikchandani, S., Hirshleifer, D. and Welch, I., 1992, "A theory of fads, fashion, custom and cultural change as informational cascades," Journal of Political Economy 100, 992-1026.

Brav, A., Constantinides, G. and Gezcy, C., 1999, "Asset pricing with heterogeneous consumers and limited participation: Empirical evidence," University of Chicago working paper.

Campbell, J.Y., Cocco, J.F., Gomes, F.J. and Maenhout, P.J., 1999, “Investing retirement wealth: A life-cycle model," Harvard University working paper.

Case, A. and Katz, L., 1991, “The company you keep: The effect of family and neighborhood on disadvantaged youths," NBER working paper.

Chiteji, N.S. and Stafford, F.P., 1999, "Portfolio choices of parents and their children as young adults: Asset accumulation by African-American families," American Economic Review Papers and Proceedings 89, 377-380.

Choi, J.J., Laibson, D. and Metrick, A., (2000), "Does the internet increase trading? Evidence from investor behavior in 401(k) plans," NBER working paper 7878. 
Cooper, I. and Kaplanis, E., 1994, "Home bias in equity portfolios, inflation hedging and international capital market equilibrium," Review of Financial Studies 7, 45-60.

Coval, J. and Moskowitz, T., 1999, "Home bias at home: Local equity preference in domestic portfolios," Journal of Finance 54, 2045-2073.

Duflo, E. and Saez, E., 2000, "Participation and investment decisions in a retirement plan: The influence of colleagues' choices," forthcoming in Journal of Public Economics.

Ellison, G. and Fudenberg, D., 1993, "Rules of thumb for social learning," Journal of Political Economy 101, 93-126.

Ellison, G. and Fudenberg, D., 1995, "Word of mouth communication and social learning," Quarterly Journal of Economics 110, 93-125.

French, K. and Poterba, J., 1991, "Investor diversification and international equity markets," American Economic Review 81, 222-226.

Glaeser, E.L., Sacerdote, B., and Scheinkman, J., 1996, "Crime and social interactions," Quarterly Journal of Economics CXIV, 502-548.

Glaeser, E.L. and Scheinkman, J., 2000, “Non-market interactions,” NBER working paper 8053.

Granovetter, M., 1983, "The strength of weak ties: A network theory revisited", Sociological Theory 1, 201-233.

Grinblatt, M. and Keloharju, M, 2000, "The investment behavior and performance of various investor-types: A study of Finland's unique data set," Journal of Financial Economics 55, 43-67.

Guiso, L., Sapienza, P. and Zingales, L., 2000, "The role of social capital in financial development," University of Chicago working paper.

Heaton, J. and Lucas, D., 1999, "Stock Prices and Fundamentals," NBER Macroeconomics Annual 14, 213-242.

Huberman, G., 1998, “Familiarity breeds investment,” Columbia University working paper.

Kang, J. and Stulz, R., 1997, "Why is there a home bias? An analysis of foreign portfolio equity ownership in Japan," Journal of Financial Economics 46, 3-28.

Kelly, M. and Grada, C.O., 2000, "Market contagion: Evidence from the Panics of 1854 and 1857," American Economic Review 90, 1110-1124.

Madrian, B. and Shea, D., 2000, "Peer effects and savings behavior in employer-sponsored savings plans," University of Chicago working paper. 
Mankiw, N.G. and Zeldes, S.P., 1991, "The consumption of stock holders and nonstockholders," Journal of Financial Economics 29, 97-112.

Mehra, R. and Prescott, E.C., 1985, “The equity premium: A puzzle," Journal of Monetary Economics 15, 145-161.

Putnam, R., 1993, Making democracy work: Civic traditions in modern Italy, Princeton University Press.

Sacerdote, B., 2000, "Peer effects with random assignment: Results for Dartmouth roommates," NBER working paper.

Shiller, R.J. and Pound, J., 1989, "Survey evidence on diffusion of interest and information among investors," Journal of Economic Behavior and Organization 12, 47-66.

Tesar, L., and Werner, I., 1995, "Home bias and high turnover," Journal of International Money and Finance 14, 467-492.

Vissing-Jorgensen, A., 1999, "Limited stock market participation and the equity premium puzzle," University of Chicago working paper.

Vissing-Jorgensen, A., 2000, "Towards an explanation of household portfolio choice heterogeneity: Nonfinancial income and participation cost structures," University of Chicago working paper. 
Table 1: Stock-Market Participation Rates for Different Categories of Households

Panel A: Stock Market Participation Rates by Race, Education and Non-Stock Market Wealth

\begin{tabular}{|c|c|c|c|c|c|c|}
\hline & \multirow[b]{2}{*}{ All } & \multicolumn{3}{|c|}{ Racial Groups } & \multicolumn{2}{|c|}{ Education Levels } \\
\hline & & White and Not Hispanic & Non-Wh & spanic & College Graduate & No College Degree \\
\hline & $(1)$ & $(2)$ & \multicolumn{2}{|c|}{$(3)$} & $(4)$ & $(5)$ \\
\hline All Households & $26.70 \%$ & $34.28 \%$ & \multicolumn{2}{|c|}{$9.21 \%$} & $49.53 \%$ & $19.97 \%$ \\
\hline $1^{\text {st }}$ Quintile of Wealth Distribution & $3.41 \%$ & $6.39 \%$ & \multicolumn{2}{|c|}{$1.17 \%$} & $6.36 \%$ & $3.17 \%$ \\
\hline $2^{\text {nd }}$ Quintile of Wealth Distribution & $11.34 \%$ & $15.28 \%$ & \multicolumn{2}{|c|}{$5.37 \%$} & $27.01 \%$ & $9.28 \%$ \\
\hline $3^{\text {rd }}$ Quintile of Wealth Distribution & $24.10 \%$ & $27.81 \%$ & \multicolumn{2}{|c|}{$13.32 \%$} & $36.36 \%$ & $20.91 \%$ \\
\hline $4^{\text {th }}$ Quintile of Wealth Distribution & $39.84 \%$ & $43.73 \%$ & \multicolumn{2}{|c|}{$21.32 \%$} & $50.11 \%$ & $35.42 \%$ \\
\hline $5^{\text {th }}$ Quintile of Wealth Distribution & $55.03 \%$ & $57.45 \%$ & \multicolumn{2}{|c|}{$35.93 \%$} & $68.38 \%$ & $44.39 \%$ \\
\hline \multicolumn{7}{|c|}{ Panel B: Stock Market Participation Rates by Sociability and Non-Stock Market Wealth } \\
\hline & \multicolumn{2}{|c|}{ Know Neighbors } & \multicolumn{2}{|c|}{ Visit Neigbors } & \multicolumn{2}{|c|}{ Attend Church } \\
\hline & Not Social & Social & Not Social & Social & Not Social & Social \\
\hline & $(1)$ & $(2)$ & $(3)$ & $(4)$ & $(5)$ & $(6)$ \\
\hline All Households & $12.33 \%$ & $27.79 \%$ & $22.77 \%$ & $28.92 \%$ & $23.52 \%$ & $27.70 \%$ \\
\hline $1^{\text {st }}$ Quintile of Wealth Distribution & $2.05 \%$ & $3.67 \%$ & $3.63 \%$ & $3.22 \%$ & $4.05 \%$ & $3.16 \%$ \\
\hline $2^{\text {nd }}$ Quintile of Wealth Distribution & $11.40 \%$ & $11.34 \%$ & $11.46 \%$ & $11.27 \%$ & $12.24 \%$ & $11.02 \%$ \\
\hline $3^{\text {rd }}$ Quintile of Wealth Distribution & $14.29 \%$ & $24.52 \%$ & $22.20 \%$ & $25.05 \%$ & $23.59 \%$ & $24.25 \%$ \\
\hline $4^{\text {th }}$ Quintile of Wealth Distribution & $30.91 \%$ & $40.18 \%$ & $37.03 \%$ & $41.17 \%$ & $37.14 \%$ & $40.56 \%$ \\
\hline $5^{\text {th }}$ Quintile of Wealth Distribution & $41.18 \%$ & $55.52 \%$ & $50.86 \%$ & $56.92 \%$ & $50.49 \%$ & $56.21 \%$ \\
\hline
\end{tabular}


Table 2: Means and Correlations of Sociability Measures and Other Independent Variables

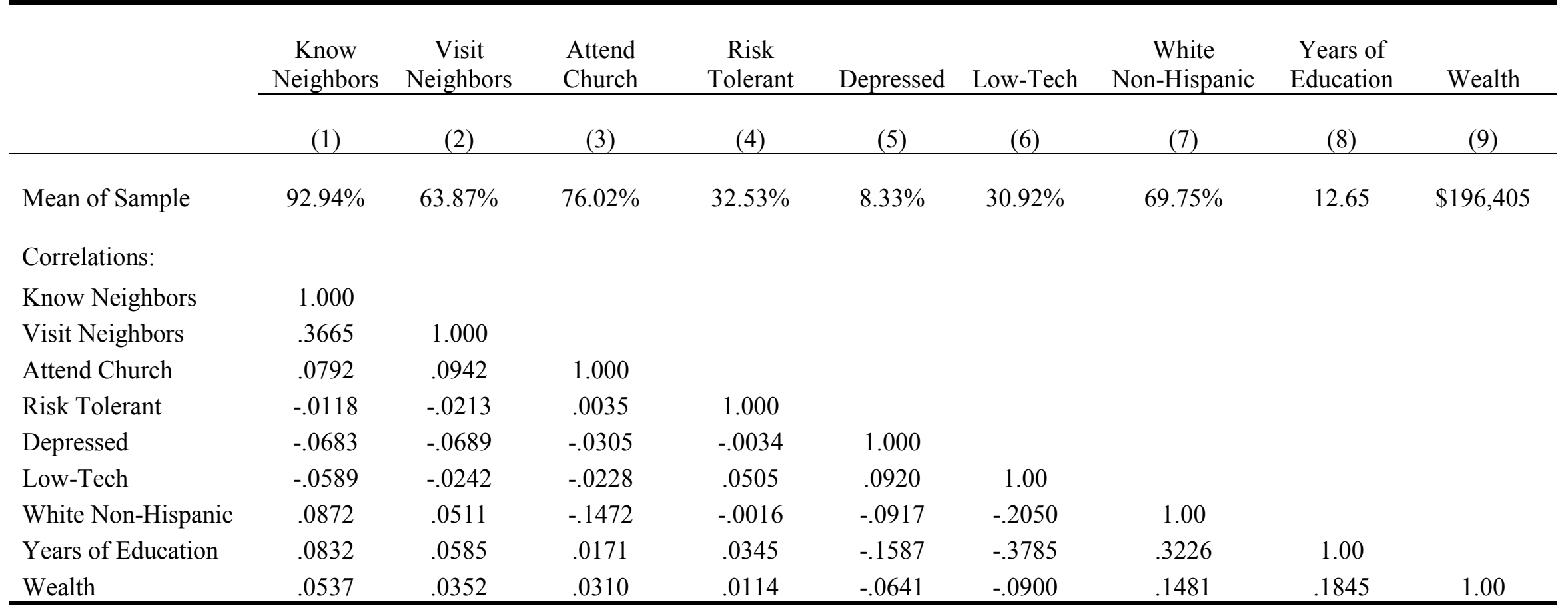


Table 3: Baseline Effect of Sociability on Whether a Household Owns Stocks

\begin{tabular}{|c|c|c|c|c|c|c|c|c|c|}
\hline & \multicolumn{3}{|c|}{ Know Neighbors } & \multicolumn{3}{|c|}{ Visit Neighbors } & \multicolumn{3}{|c|}{ Attend Church } \\
\hline & (1) & (2) & (3) & (4) & (5) & $(6)$ & (7) & $(8)$ & (9) \\
\hline Sociability Indicator & $\begin{array}{l}.0411^{* * *} \\
(.0141)\end{array}$ & $\begin{array}{l}.0406^{* * *} \\
(.0142)\end{array}$ & $\begin{array}{l}.0405^{* * *} \\
(.0141)\end{array}$ & $\begin{array}{l}.0215^{* *} \\
(.0093)\end{array}$ & $\begin{array}{l}.0218^{* *} \\
(.0093)\end{array}$ & $\begin{array}{l}.0247^{* * *} \\
(.0093)\end{array}$ & $\begin{array}{l}.0369^{* * *} \\
(.0109)\end{array}$ & $\begin{array}{l}.0355^{* * *} \\
(.0109)\end{array}$ & $\begin{array}{l}.0268^{* *} \\
(.0109)\end{array}$ \\
\hline Risk Tolerance Indicator & $\begin{array}{l}.0367^{* * *} \\
(.0099)\end{array}$ & $\begin{array}{l}.0369^{* * *} \\
(.0099)\end{array}$ & $\begin{array}{l}.0311^{* * * *} \\
(.0099)\end{array}$ & $\begin{array}{l}.0369^{* * * *} \\
(.0099)\end{array}$ & $\begin{array}{l}.0371^{* * * *} \\
(.0099)\end{array}$ & $\begin{array}{l}.0314^{* * *} \\
(.0099)\end{array}$ & $\begin{array}{l}.0364^{* * *} \\
(.0099)\end{array}$ & $\begin{array}{l}.0366^{* * *} \\
(.0099)\end{array}$ & $\begin{array}{l}.0307^{* * *} \\
(.0099)\end{array}$ \\
\hline Years of Education & $\begin{array}{l}.0231^{* * *} \\
(.0015)\end{array}$ & $\begin{array}{l}.0230^{* * *} \\
(.0015)\end{array}$ & & $\begin{array}{l}.0231^{* * * *} \\
(.0015)\end{array}$ & $\begin{array}{l}.0229^{* * * *} \\
(.0015)\end{array}$ & & $\begin{array}{l}.0230^{* * * *} \\
(.0015)\end{array}$ & $\begin{array}{l}.0228^{* * * *} \\
(.0015)\end{array}$ & \\
\hline Age & $\begin{array}{c}.0005 \\
(.0010)\end{array}$ & $\begin{array}{l}.0005 \\
(.0010)\end{array}$ & & $\begin{array}{l}.0005 \\
(.0010)\end{array}$ & $\begin{array}{l}.0005 \\
(.0010)\end{array}$ & & $\begin{array}{l}.0005 \\
(.0010)\end{array}$ & $\begin{array}{l}.0005 \\
(.0010)\end{array}$ & \\
\hline White/Non-Hispanic Indicator & $\begin{array}{l}.0995^{* * *} \\
(.0096)\end{array}$ & $\begin{array}{l}.1003^{* * *} \\
(.0096)\end{array}$ & $\begin{array}{l}.0990^{* * *} \\
(.0105)\end{array}$ & $\begin{array}{l}.0998^{* * *} \\
(.0096)\end{array}$ & $\begin{array}{l}.1005^{* * *} \\
(.0097)\end{array}$ & $\begin{array}{l}.0988^{* * *} \\
(.0105)\end{array}$ & $\begin{array}{l}.1069^{* * *} \\
(.0099)\end{array}$ & $\begin{array}{l}.1075^{* * *} \\
(.0100)\end{array}$ & $\begin{array}{l}.1044^{* * *} \\
(.0108)\end{array}$ \\
\hline Urban Indicator & $\begin{array}{l}.0605^{* * *} \\
(.0166)\end{array}$ & $\begin{array}{l}.0622^{* * *} \\
(.0166)\end{array}$ & $\begin{array}{l}.0481^{* * * *} \\
(.0168)\end{array}$ & $\begin{array}{l}.0599^{* * * *} \\
(.0166)\end{array}$ & $\begin{array}{l}.0616^{* * *} \\
(.0166)\end{array}$ & $\begin{array}{l}.0477^{* * *} \\
(.0168)\end{array}$ & $\begin{array}{l}.0600^{* * *} \\
(.0166)\end{array}$ & $\begin{array}{l}.0616^{* * *} \\
.0166)\end{array}$ & $\begin{array}{l}.0476^{* * *} \\
(.0168)\end{array}$ \\
\hline $2^{\text {nd }}$ Quintile of Wealth Distribution & $\begin{array}{l}.0281^{* * *} \\
(.0099)\end{array}$ & & & $\begin{array}{l}.0298^{* * * *} \\
(.0099)\end{array}$ & & & $\begin{array}{l}.0302^{* * *} \\
(.0099)\end{array}$ & & \\
\hline $3^{\text {rd }}$ Quintile of Wealth Distribution & $\begin{array}{l}.1156^{* * *} \\
(.0130)\end{array}$ & & & $\begin{array}{l}.1177^{* * * *} \\
(.0129)\end{array}$ & & & $\begin{array}{l}.1176^{* * *} \\
(.0129)\end{array}$ & & \\
\hline $4^{\text {th }}$ Quintile of Wealth Distribution & $\begin{array}{l}.2455^{* * *} \\
(.0149)\end{array}$ & & & $\begin{array}{l}.2476^{* * *} \\
(.0149)\end{array}$ & & & $\begin{array}{l}.2462^{* * *} \\
(.0149)\end{array}$ & & \\
\hline $5^{\text {th }}$ Quintile of Wealth Distribution & $\begin{array}{l}.3757^{* * *} \\
(.0160)\end{array}$ & & & $\begin{array}{l}.3776^{* * *} \\
(.0159)\end{array}$ & & & $\begin{array}{l}.3760^{* * * *} \\
(.0160)\end{array}$ & & \\
\hline Depressed Indicator & & & $\begin{array}{c}-.0302^{* *} \\
(.0126)\end{array}$ & & & $\begin{array}{c}-.0292^{* *} \\
(.0127)\end{array}$ & & & $\begin{array}{c}-.0306^{* *} \\
(.0126)\end{array}$ \\
\hline Low-Tech Indicator & & & $\begin{array}{c}-.0349^{* * *} \\
(.0098)\end{array}$ & & & $\begin{array}{c}-.0352^{* * *} \\
(.0098)\end{array}$ & & & $\begin{array}{c}-.0350^{* * *} \\
(.0098)\end{array}$ \\
\hline Wealth Dummies & No & Yes & Yes & No & Yes & Yes & No & Yes & Yes \\
\hline Age Dummies & No & No & Yes & No & No & Yes & No & No & Yes \\
\hline Years of Education Dummies & No & No & Yes & No & No & Yes & No & No & Yes \\
\hline Income Dummies & No & No & Yes & No & No & Yes & No & No & Yes \\
\hline State Dummies & No & No & Yes & No & No & Yes & No & No & Yes \\
\hline
\end{tabular}

Notes: The dependent variable is an indicator that the household owns stock. The specification also includes marital status dummies and a sexof-respondent dummy. Robust standard errors are in parentheses. There are 7465 household observations. ("Significant at 10 percent level.

${ }^{* *}$ Significant at 5 percent level. ${ }^{* * *}$ Significant at 1 percent level.) 


\begin{tabular}{lccc}
\hline & Know Neighbors & Visit Neighbors & Attend Church \\
\cline { 2 - 4 } & $(1)$ & $(2)$ & $(3)$ \\
\hline Sociability & $.0254^{* *}$ & -.0034 & .0038 \\
& $(.0127)$ & $(.0095)$ & $(.0114)$ \\
Sociability $\times$ White, Educated and Wealthy & .0546 & $.0628^{* * *}$ & $.0673^{* * *}$ \\
& $(.0519)$ & $(.0215)$ & $(.0240)$ \\
\hline \hline
\end{tabular}

Notes: The dependent variable is an indicator that the household owns stock. The regression specification also includes all of the control variables used in column (2) of Table 3 (a risk tolerance indicator, years of education, age, a white non-hispanic indicator, an urban indicator, twenty wealth dummies, marital status dummies and a sex-of respondent dummy). There are 7465 household observations. ("Significant at 10 percent level. ${ }^{* *}$ Significant at 5 percent level. ${ }^{* * *}$ Significant at 1 percent level.) 
Table 5: Low, Medium and High Participation States

Panel A: Raw Participation Rates

\begin{tabular}{ccc} 
Low Participation States & Medium Participation States & High Participation States \\
\hline & & \\
Alabama $(14.81 \%)$ & South Carolina $(23.91 \%)$ & Michigan $(31.31 \%)$ \\
Louisiana $(15.38 \%)$ & Florida $(24.01 \%)$ & Maryland $(32.93 \%)$ \\
Arkansas $(15.50 \%)$ & Virginia $(25.83 \%)$ & New Jersey $(33.45 \%)$ \\
Tennessee $(17.37 \%)$ & Colorado $(25.97 \%)$ & Indiana $(34.46 \%)$ \\
North Dakota $(17.39 \%)$ & California $(28.51 \%)$ & Missouri $(34.70 \%)$ \\
Texas $(18.04 \%)$ & Oklahoma $(28.57 \%)$ & New Hampshire (35.85\%) \\
North Carolina $(18.57 \%)$ & Illinois $(28.96 \%)$ & Nebraska $(37.5 \%)$ \\
Mississippi $(18.58 \%)$ & Oregon $(29.09 \%)$ & Kansas $(39.02 \%)$ \\
Georgia $(19.44 \%)$ & Massachusetts $(29.25 \%)$ & Wisconsin $(39.82 \%)$ \\
District of Columbia $(21.73 \%)$ & Ohio $(29.38 \%)$ & Connecticut $(40.95 \%)$ \\
New York $(21.76 \%)$ & Iowa $(30.00 \%)$ & Washington $(40.96 \%)$ \\
Arizona $(21.88 \%)$ & Pennsylvania $(31.11 \%)$ & Minnesota $(44.22 \%)$ \\
West Virginia $(23.68 \%)$ & & Wyoming $(45.83 \%)$
\end{tabular}

Panel B: Abnormal Participation Rates (Residual Relative to Median State: Iowa)

\begin{tabular}{ccc} 
Low Participation States & Medium Participation States & High Participation States \\
\hline North Dakota $(-17.27 \%)$ & Florida $(-1.75 \%)$ & South Carolina $(2.76 \%)$ \\
Massachusetts $(-7.72 \%)$ & New York $(-1.32 \%)$ & Maryland $(3.12 \%)$ \\
Tennessee $(-7.24 \%)$ & Illinois $(-0.42 \%)$ & Pennsylvania $(3.18 \%)$ \\
Arkansas $(-7.11 \%)$ & Virginia $(-0.17 \%)$ & Missouri $(3.19 \%)$ \\
Louisiana $(-6.43 \%)$ & Oklahoma $(-0.11 \%)$ & Michigan $(3.63 \%)$ \\
Alabama $(-6.26 \%)$ & Iowa $(0 \%)$ & Kansas $(3.92 \%)$ \\
New Hampshire $(-5.33 \%)$ & Washington $(0 \%)$ & Ohio $(4.10 \%)$ \\
Oregon $(-4.61 \%)$ & North Carolina $(0.43 \%)$ & Connecticut $(5.51 \%)$ \\
Mississippi $(-4.13 \%)$ & New Jersey $(1.54 \%)$ & Nebraska $(5.79 \%)$ \\
Arizona $(-2.02 \%)$ & Georgia $(2.00 \%)$ & Indiana $(6.18 \%)$ \\
Colorado $(-1.97 \%)$ & District of Columbia $(2.03 \%)$ & Wisconsin $(8.23 \%)$ \\
California $(-1.83 \%)$ & Texas $(2.15 \%)$ & Minnesota $(9.60 \%)$ \\
West Virginia $(-1.77 \%)$ & & Wyoming $(15.21 \%)$ \\
\hline \hline
\end{tabular}

Notes: A state's raw participation rate is the fraction of households in the state that own stock. A state's abnormal participation rate is its average residual in a regression of participation against all of the controls in column (1) of Table 3 except for the sociability indicator (a risk tolerance indicator, years of education, age, a white non-hispanic indicator, an urban indicator, five wealth dummies, marital status dummies and a sex-of respondent dummy). 
Table 6: Interactions of Sociability and Risk Tolerance with State-Level Participation Rates

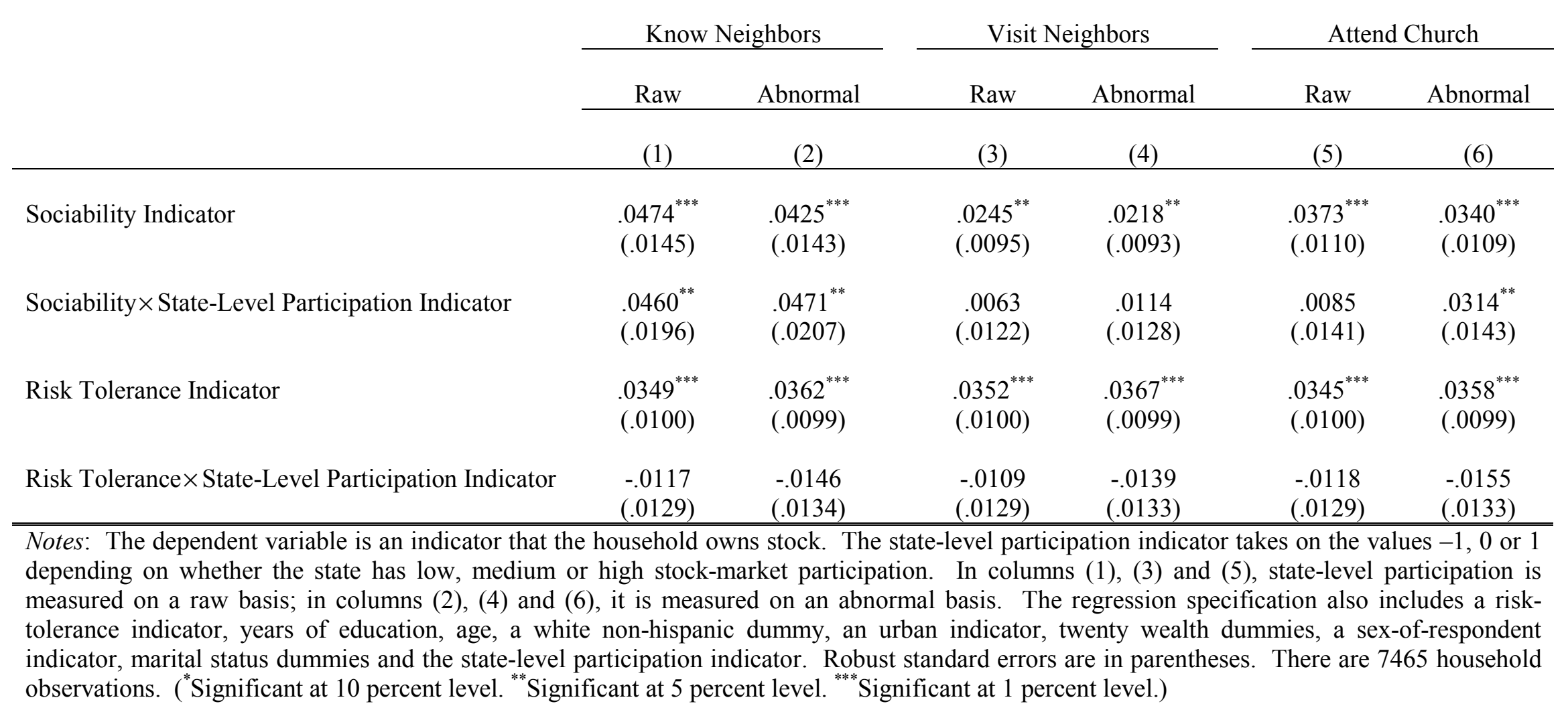


(1)

$.0204^{* *}$

$.0239^{* * *}$

$(.0015)$

.0004

$(.0010)$

$.0956^{* * *}$

$(.0094)$

$.0282^{* * *}$

$(.0099)$

$3^{\text {rd }}$ Quintile of Wealth Distribution

$.1133^{* * *}$

$(.0129)$

$4^{\text {th }}$ Quintile of Wealth Distribution

$.2449^{* * *}$

$(.0149)$

$5^{\text {th }}$ Quintile of Wealth Distribution
$.3726^{* * *}$

(.0159)
(2)

$.0238^{* * *}$

(.0045)

.0030

(.0036)

$.0769^{* * *}$

(.0260)

$.0812^{* * *}$

(.0353)

$.1429^{* * *}$

(.0369)

$.2971^{* * *}$

(.0383)

$.4676^{* * *}$

(.0394)

Observations

7465

1441

Notes: The dependent variable is an indicator that the household owns stock. The sociability measure is an indicator whether a household visits neighbors. Robust standard errors are in parentheses. ( ${ }^{*}$ Significant at 10 percent level. ${ }^{* *}$ Significant at 5 percent level. ${ }^{* * *}$ Significant at 1 percent level.) 
Table 8: The Effect of Sociability on Whether a Household Has a Checking Account

\begin{tabular}{|c|c|c|c|}
\hline & Know Neighbors & Visit Neighbors & Attend Church \\
\hline & $(1)$ & $(2)$ & $(3)$ \\
\hline Sociability Indicator & $\begin{array}{l}-.0116 \\
(.0175)\end{array}$ & $\begin{array}{c}-.0062 \\
(.0081)\end{array}$ & $\begin{array}{c}.0132 \\
(.0092)\end{array}$ \\
\hline Risk Tolerance Indicator & $\begin{array}{c}-.0247^{* * *} \\
(.0084)\end{array}$ & $\begin{array}{c}-.0248^{* * *} \\
(.0084)\end{array}$ & $\begin{array}{c}-.0246^{* * *} \\
(.0084)\end{array}$ \\
\hline Years of Education & $\begin{array}{l}.0235^{* * *} \\
(.0016)\end{array}$ & $\begin{array}{l}.0235^{* * *} \\
(.0016)\end{array}$ & $\begin{array}{l}.0234^{* * *} \\
(.0016)\end{array}$ \\
\hline Age & $\begin{array}{c}.0006 \\
(.0008)\end{array}$ & $\begin{array}{c}.0006 \\
(.0008)\end{array}$ & $\begin{array}{l}.0005 \\
(.0008)\end{array}$ \\
\hline White/Non-Hispanic Indicator & $\begin{array}{l}.1357^{* * *} \\
(.0109)\end{array}$ & $\begin{array}{l}.1356^{* * *} \\
(.0109)\end{array}$ & $\begin{array}{l}.1380^{* * *} \\
(.0110)\end{array}$ \\
\hline Urban Indicator & $\begin{array}{l}.0341^{* *} \\
(.0141)\end{array}$ & $\begin{array}{l}.0343^{* *} \\
(.0141)\end{array}$ & $\begin{array}{l}.0346^{* *} \\
(.0141)\end{array}$ \\
\hline
\end{tabular}

Notes: The dependent variable is an indicator that the household has a checking account. The regression specification also includes twenty wealth dummies, marital status dummies and a sex-ofrespondent dummy. Robust standard errors in parentheses. There are 7465 household observations. $78.22 \%$ of the households have checking accounts. ("Significant at 10 percent level. ${ }^{* *}$ Significant at 5 percent level. ${ }^{* * *}$ Significant at 1 percent level.) 